\title{
Decreased aEEG Continuity and Baseline Variability in the First 48 Hours of Life Associated With Poor Short-Term Outcome in Neonates Born Before 29 Weeks Gestation
}

\author{
JENNIFER R. BOWEN, MARY PARADISIS, AND DHARMESH SHAH
}

\begin{abstract}
Department of Neonatology [J.R.B., M.P., D.S.], Royal North Shore Hospital, St Leonards, New South Wales 2065, Australia; Department of Neonatology [M.P.], Royal Prince Alfred Hospital, Camperdown, New South Wales 2050, Australia; Discipline of Obstetrics, Gynaecology and Neonatology [J.R.B., M.P.], Sydney Medical School, University of Sydney, New South Wales 2006, Australia
\end{abstract}

\begin{abstract}
Amplitude-integrated electroencephalography (aEEG) provides us with a method of assessing brain activity in critically ill neonates. In extremely premature neonates, the aEEG trace is predominantly discontinuous, making it difficult to distinguish between a "normal" and "abnormal" trace. We measured aEEG activity in the first $48 \mathrm{~h}$ of life in neonates born before 29-wk gestation and used both visual and quantitative analysis of the aEEG data to assess differences in neonates with poor short-term outcome [death or peri/intraventricular hemorrhage $(\mathrm{P} / \mathrm{IVH})]$ compared with those who survived without P/IVH to identify features of an abnormal aEEG. On quantitative analysis, EEG continuity $<80 \%$ at $10-\mu \mathrm{V}$ level was a sensitive and specific marker of poor short-term outcome. By using this marker, we identified $83 \%$ of neonates who died or developed grade 3 or 4 IVH and $60 \%$ of neonates who developed grades 1 or 2 IVH, with a positive predictive value for death or any IVH of $73 \%$ and a negative predictive value of $86 \%$. Absence of sleep-wake cycling with baseline variability $<2 \mu \mathrm{V}$ was the strongest predictor of outcome using visual analysis alone. (Pediatr Res 67: 538-544, 2010)
\end{abstract}

$\mathrm{E}$ xtremely premature neonates have been provided with life-saving intensive care support in neonatal intensive care units (NICUs) for more than three decades. As survival rates for these infants have improved, an increasing emphasis is being placed on the quality of survival and long-term neurologic outcome in these vulnerable children $(1,2)$.

Cardiorespiratory monitoring is performed as standard care in neonatal units. Monitoring of brain function is more difficult. Electroencephalography (EEG) monitoring is a sensitive method for detection of brain injury in preterm infants (3-6); however, the fragile nature of the extremely premature neonate makes it difficult to perform long-term monitoring using multichannel EEG recordings and is particularly difficult during the first few days of life when the neonate is often critically unwell.

Limited channel amplitude-integrated EEG (aEEG) monitoring provides a simplified form of EEG monitoring that can be performed over prolonged periods of time in the NICU. In full-term neonates, aEEG monitoring is used in the first few days of life for neonates with encephalopathy or risk of seizures to help guide treatment and to assist with prognosis (7-15).

Received July 31, 2009; accepted December 20, 2009

Correspondence: Jennifer Bowen, M.B.B.S., F.R.A.C.P., Department of Neonatology, Royal North Shore Hospital, St Leonards, New South Wales 2065, Australia; e-mail: jbowen@med.usyd.edu.au
The role of aEEG monitoring in the premature neonate is less clear. The EEG in the premature neonate is predominantly discontinuous, with bursts of activity alternating with periods of relative attenuation $(6,16,17)$. The sleep-wake pattern seen in the aEEG recording of the mature full-term neonate is poorly developed in the preterm neonate. The general immaturity of the EEG trace in the extremely premature neonate results in difficulty distinguishing between a "normal" and "abnormal" aEEG trace in these neonates. A number of studies have assessed aEEG recordings of premature neonates during the first few weeks of life (18-23); however, few studies have assessed extremely premature neonates in the first $48 \mathrm{~h}$ after birth $(24,25)$. Quantitative aEEG analysis has been performed in some recent studies, which have shown associations between quantitative measures and outcome $(20,23,25)$.

The aims of this study were to:

1. Identify features of a normal aEEG trace in the first $48 \mathrm{~h}$ of life in neonates $<29$-wk gestation who survived without peri/intraventricular hemorrhage $(\mathrm{P} / \mathrm{IVH})$, using visual analysis and quantitative measures.

2. Identify features of an abnormal aEEG trace, by assessing differences in the aEEG recordings between neonates who survived without P/IVH and those who died or developed P/IVH.

\section{METHODS}

Subjects. Neonates with gestational age $<29$ wk admitted to two tertiary level NICUs at Royal North Shore Hospital (RNSH) and Royal Prince Alfred Hospital (RPAH), Sydney, Australia, were recruited to this prospectively performed cohort study. The study was approved by the Human Research Ethics Committee and Clinical Trials Committee of both hospitals. Written informed parental consent was obtained for all neonates.

Perinatal/neonatal factors recorded included the following: birth weight (BW), gestational age at birth (GA), sex, mode of delivery, cord blood $\mathrm{pH}$, Apgar score at 1 and $5 \mathrm{~min}$, mean blood pressure (BP), mechanical ventilation, and use of inotropes (dopamine or dobutamine), sedatives, and anticonvulsants. Treatment with inotropes was at the discretion of the clinician but was generally given for low $\mathrm{BP}$ (mean $\mathrm{BP}<24 \mathrm{~mm} \mathrm{Hg}$ ) or clinical and cardiac ultrasound signs of poor perfusion [low cardiac output or low superior vena cava flow (26)].

Abbreviations: aEEG, amplitude integrated electroencephalography; P/IVH, peri/intraventricular hemorrhage 
Amplitude-integrated EEG. Two channel aEEG traces were recorded continuously from $10-48 \mathrm{~h}$ of life with the Brainz Instruments BRM2 monitor (Brainz Instrument Ltd, New Zealand), using hydrogel electrodes, with standard electrode placement at C3, P3, C4, and P4 regions (International 10-20 system). The transformation of the EEG signal into the amplitudeintegrated trace has been described elsewhere $(20,23)$. The EEG signal is filtered, rectified, amplitude integrated, and compressed to display $1 \mathrm{~h}$ of recording per $6 \mathrm{~cm}$. All aEEG recordings were obtained by two investigators (M.P. and D.S.).

aEEG recordings were analyzed for three 2-h epochs at 12-14 h, 24-26 h, and 46-48 h. Data were analyzed when there was at least $60 \mathrm{~min}$ of satisfactory recording within the 2 -h epoch, with impedance $<15 \mathrm{kOhm}$ per electrode pair. Cross-cerebral P3-P4 aEEG recordings were analyzed to provide comparison with single-channel aEEG monitors.

Visual analysis of the aEEG. Each 2-h epoch was analyzed visually to assess background pattern and baseline variability, using criteria modified from Hellstrom-Westas et al. (27). Visual analysis was performed with the observer blinded to quantitative analysis of the aEEG and outcome of the neonate. Periods of trace affected by seizures or obvious artifact were excluded from visual analysis. Background pattern was classified primarily using the aEEG minimum amplitude.

aEEG background pattern (Fig. 1)

1. Continuous: periods of continuous activity with minimum amplitude $>5$ $\mu \mathrm{V}$ identified for at least one 10-min period of the 2-h trace;

2. Discontinuous: predominantly discontinuous pattern, with minimal amplitude $2-5 \mu \mathrm{V}$ for $>50 \%$ of trace;

3. Suppressed: predominantly suppressed trace, with minimum amplitude $<2$ $\mu \mathrm{V}$ for $>50 \%$ of trace (27).

aEEG baseline variability (sleep-wake cycling; Fig. 1):

1. Developed sleep-wake cycling: clearly identifiable sinusoidal variation between discontinuous and continuous background activity, with cycle duration and periods of continuity $\geq 20 \mathrm{~min}$;

2. Immature sleep-wake cycling: some cyclic variation of aEEG baseline amplitude (variation $>2 \mu \mathrm{V}$ ), predominantly between discontinuous low voltage and discontinuous high voltage patterns, with cycle duration $<20$ $\min$;

3. No sleep-wake cycling: variation in aEEG baseline $<2 \mu \mathrm{V}$ throughout trace.

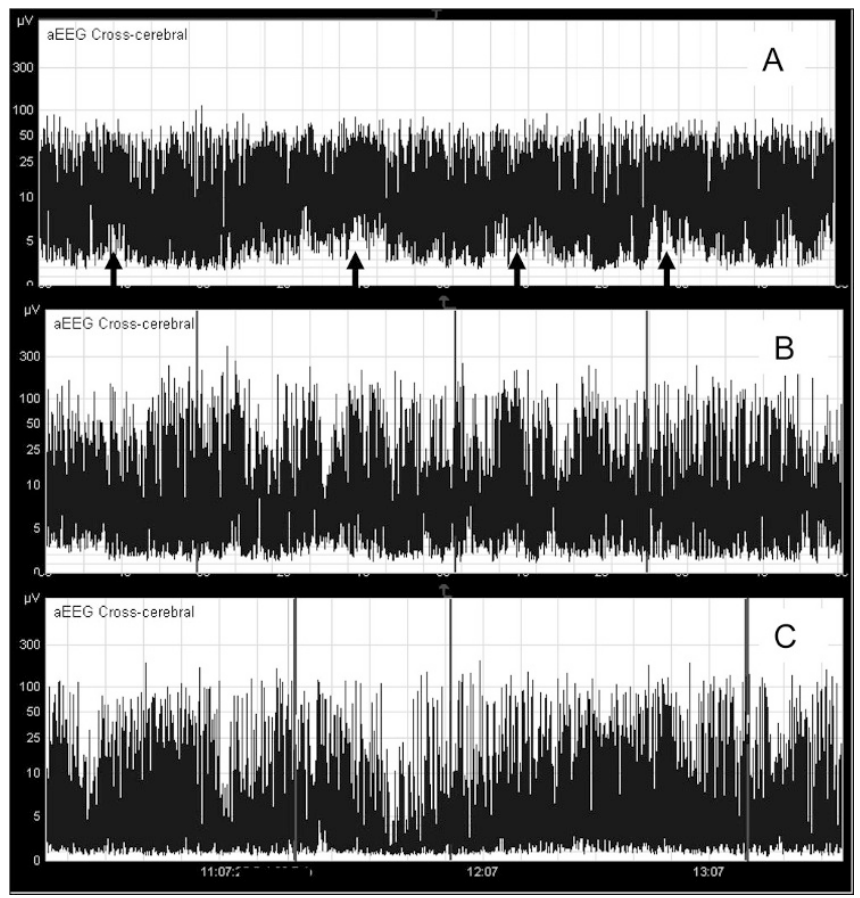

Figure 1. Cross-cerebral (P3-P4) aEEG recording. A, Periods of continuity with baseline $>5 \mu \mathrm{V}$ (identified with arrows). Developed sleep-wake cycles with sinusoidal variation $>20$-min duration. $B$, Discontinuous baseline $2-5$ $\mu \mathrm{V}$. Immature sleep-wake cycling: baseline variability $>2 \mu \mathrm{V}$. $C$, Suppressed trace: baseline $<2 \mu \mathrm{V}$. No sleep-wake cycling: baseline variability $<2 \mu \mathrm{V}$.
Quantitative analysis of the aEEG. Quantitative measurements of cross cerebral P3-P4 recordings were analyzed off-line to obtain EEG continuity and aEEG amplitude using the Brainz Analyze Research version 1.5 software (Brainz Instruments). EEG data were assessed every $2 \mathrm{~s}$, then averaged, and recorded at 1-min intervals (23).

Quantitative EEG continuity measures were determined for each 2-h epoch as the percentage of time during which the amplitude of the raw EEG was above a predetermined threshold $(10,25$, and $50 \mu \mathrm{V})(23)$.

The mean $\pm \mathrm{SD}$ of the maximum, mean, and minimum aEEG amplitude was calculated for each 2-h epoch. The SD of the minimum aEEG amplitude (SD minimum amplitude) was recorded as a quantitative measure of baseline variability.

Cranial ultrasounds scans. Serial scans were performed at 6-12 h, 24-48 h, d 3-7, d 28-30, and 36-wk postconceptional age, using a GE Vivid 7 ultrasound machine (GE Healthcare). Cranial ultrasounds were assessed for $\mathrm{P} / \mathrm{IVH}$ and structural abnormalities. $\mathrm{P} / \mathrm{IVH}$ was classified according to Papille et al. (28).

Neonatal outcomes. Survival to discharge and grade of P/IVH were recorded. Neonates were categorized into three groups: survivors without $\mathrm{P} / \mathrm{IVH}$; survivors with grades 1-2 IVH; and neonates who died or developed grades 3-4 P/IVH.

Statistical analysis. Statistical analysis was performed using SPSS Statistics 17.0 (SPSS, Chicago, IL). Perinatal variables, EEG, and aEEG measures for survivors and neonates who died or developed P/IVH were compared using Mann-Whitney $U$ and Kruskal-Wallis tests for continuous variables, and Pearson $\chi^{2}$ test to assess difference in proportions. The Friedman test for related nonparametric samples was used to assess changes in EEG and aEEG measures over time (at 12,24 , and $48 \mathrm{~h}$ ) for each group.

\section{RESULTS}

Subjects. Sixty-five neonates born at $<29$ wk gestation were enrolled between January 2004 and August 2008. Twenty-one (32\%) were born at 24-25 wk gestation and $44(68 \%)$ at 26-28 wk gestation. The median GA was 26 wk (range, 24-28 wk), and the median BW was $865 \mathrm{~g}$ (range, 428-1417 g). Fifty-five neonates survived, 43 (78\%) had no P/IVH, 10 (18\%) had grades 1-2 IVH, and two (4\%) had grades 3-4 $\mathrm{P} / \mathrm{IVH}$. Ten neonates died, five with grades 3-4 P/IVH. Grades 3-4 P/IVH was identified before $12 \mathrm{~h}$ in two neonates and at $30-48 \mathrm{~h}$ in five neonates. Death occurred before $48 \mathrm{~h}$ in three neonates, the remainder died between 3 and $53 \mathrm{~d}$. Eighteen neonates $(28 \%)$ required inotrope support.

There were no significant differences in characteristics at birth among the survivors compared with those who died or developed P/IVH. Neonates who died or developed P/IVH had a lower mean BP at $12 \mathrm{~h}$ and were more likely to be supported with inotropes at $24 \mathrm{~h}$ (Table 1).

A total of 182 EEG epochs were analyzed: 62 at $12-14 \mathrm{~h}$, 64 at $24-26$ h, and 56 at 46-48 h. Fifty-two neonates had complete recordings for all three time epochs. Three neonates died before $48 \mathrm{~h}$, and 10 recordings were excluded because of technical difficulties.

Features of the normal aEEG seen in neonates who survived without $\mathbf{P} / \mathbf{I V H}$. On visual analysis of the aEEG, the majority of neonates who survived without P/IVH had a discontinuous aEEG background pattern (aEEG baseline $\geq 2$ $\mu \mathrm{V}$ ), with immature sleep-wake cycling (baseline variability $>2 \mu \mathrm{V})$. Periods of continuity with aEEG baseline $>5 \mu \mathrm{V}$ were seen in $21 \%$ at $24 \mathrm{~h}$, and developed sleep-wake cycling was occasionally seen $(<10 \%$; Figs. 2 and 3$)$. 
Table 1. Perinatal data

\begin{tabular}{|c|c|c|c|c|}
\hline & $\begin{array}{c}\text { Survivors, no P/IVH, } \\
\quad n=43\end{array}$ & $\begin{array}{c}\text { Survivors, grades } 1-2 \mathrm{IVH}, \\
n=10\end{array}$ & $\begin{array}{c}\text { Died or grades 3-4 P/IVH, } \\
\qquad n=12\end{array}$ & $P$ \\
\hline Gestational age (wk) & $26(25-28)$ & $26(25.7-27)$ & $26(24-26.8)$ & NS \\
\hline $24-25 \mathrm{wk}, n(\%)$ & $14(33)$ & $2(20)$ & $5(42)$ & NS \\
\hline Birth weight $(\mathrm{g})$ & $850(726-1030)$ & $882(792-964)$ & $741(554-962)$ & NS \\
\hline Apgar $1 \mathrm{~min}$ & $6(3-7)$ & $3(2-6)$ & $6(5-8)$ & NS \\
\hline Apgar 5 min & $8(6-9)$ & $6(5-8)$ & $7(7-9)$ & NS \\
\hline Cord $\mathrm{pH}$ & $7.3(7.2-7.4)$ & $7.3(7.2-7.4)$ & $7.4(7.3-7.4)$ & NS \\
\hline Male sex, $n(\%)$ & $24(56)$ & $5(50)$ & $4(33)$ & NS \\
\hline Cesarean section, $n(\%)$ & $28(65)$ & $6(60)$ & $6(50)$ & NS \\
\hline Mean $\mathrm{BP}$ at $12 \mathrm{~h}$ & $32(29-36)$ & $28(23-33)$ & $27(22-32)$ & 0.018 \\
\hline Mean BP at $24 \mathrm{~h}$ & $36(30-39)$ & $32(29-33)$ & $31(27-38)$ & NS \\
\hline Mechanical ventilation at $24 \mathrm{~h}, n(\%)$ & $19(44)$ & $7(70)$ & $9(75)$ & NS \\
\hline Inotropes at $24 \mathrm{~h}, n(\%)$ & $6(14)$ & $5(50)$ & $7(58)$ & 0.002 \\
\hline Sedatives/anticonvulsants at $24 \mathrm{~h}, n(\%)$ & $1(2)$ & 0 & $2(16)$ & NS \\
\hline
\end{tabular}

Data shown as median (interquartile range) or $n(\%)$.

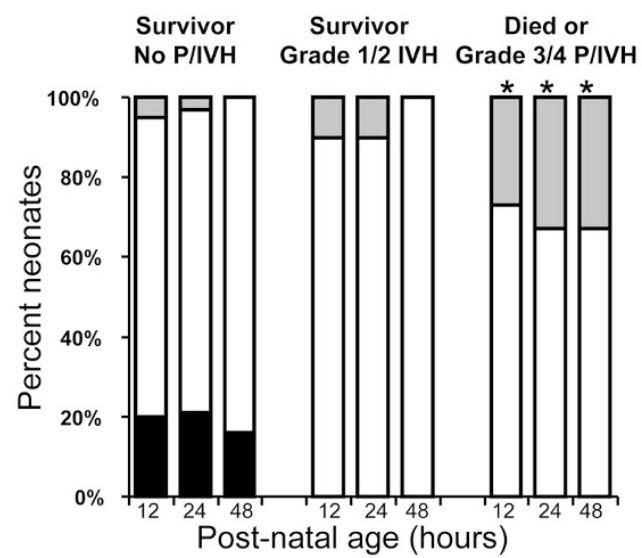

Figure 2. Proportion of neonates with aEEG background pattern classification on visual analysis: $\square$ periods of continuity, baseline $>5 \mu \mathrm{V}$ for $\geq 10 \mathrm{~min}$; $\square$ discontinuous, baseline 2-5 $\mu \mathrm{V} ; \square$ suppressed, baseline $<2 \mu \mathrm{V}$. *p $<0.05$ compared with "survivor, no P/IVH" for same time epoch.

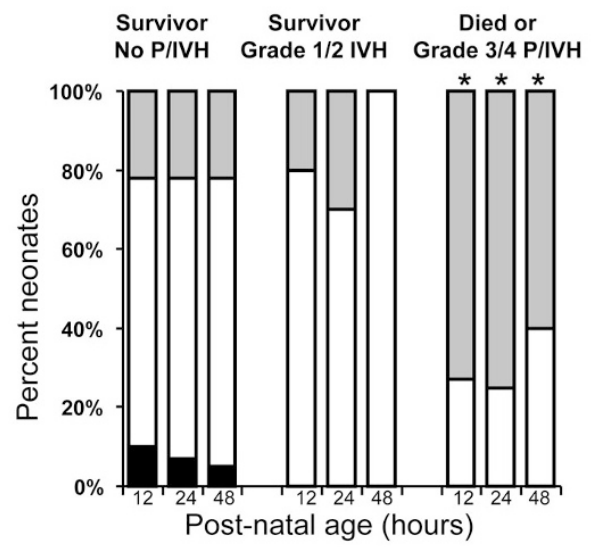

Figure 3. Proportion of neonates with aEEG baseline variability classification on visual analysis: $\square$ developed sleep-wake cycling $>20$ min cycles; $\square$ immature sleep-wake cycling, $<20$ min cycles; $\square$ no sleep-wake cycling. $* p<0.05$ compared with "survivor, no P/IVH" for same time epoch.

On quantitative analysis of the aEEG at $24 \mathrm{~h}, 86 \%$ of neonates who survived without P/IVH had EEG continuity $>80 \%$ at the $10 \mu \mathrm{V}$ level, $90 \%$ had an average maximum aEEG amplitude $\geq 12 \mu \mathrm{V}$, and in $83 \%$, the SD minimum amplitude was $>1 \mu \mathrm{V}$ (Table 2). Median percent EEG con- tinuity at 10-, 25-, and 50- $\mu \mathrm{V}$ levels and maximum, mean, and minimum aEEG amplitudes increased from 12 to $48 \mathrm{~h}$ in survivors (Friedman test, $p<0.01$; Table 3 and Fig. 4).

Features of the normal aEEG seen in neonates who died or developed P/IVH. On visual analysis, $33 \%$ of those who died or developed grade 3 or 4 P/IVH had a suppressed aEEG baseline $<2 \mu \mathrm{V}$, and $75 \%$ had no sleep-wake cycling (baseline variability $<2 \mu \mathrm{V}$ ). Periods of continuity with aEEG baseline $>5 \mu \mathrm{V}$ were not seen in any neonates who died or developed P/IVH (Figs. 2 and 3).

Neonates who died or developed P/IVH had significantly lower EEG continuity at the 10-, 25-, and 50- $\mu \mathrm{V}$ levels and lower aEEG maximum, mean, and SD minimum amplitude at $24 \mathrm{~h}$ than survivors without P/IVH (Table 3). In contrast to survivors, there was no increase in EEG continuity or aEEG amplitude from 12 to $48 \mathrm{~h}$ in neonates who died or developed grades 3-4 IVH. Neonates with grades 1-2 IVH had suppression of continuity at $24 \mathrm{~h}$, with recovery by $48 \mathrm{~h}$ (Table 3 and Fig. 4). EEG continuity $<80 \%$ at the $10-\mu \mathrm{V}$ level at $24 \mathrm{~h}$ was a strong predictor of death or IVH, with a sensitivity of $73 \%$ and specificity of $86 \%$ ( $p=0.000$; Table 2 and Fig. 5).

The SD minimum amplitude was significantly lower at both 12 and $24 \mathrm{~h}$ for neonates who died or developed P/IVH compared with those who survived without P/IVH (Table 3 ) and was strongly associated with visual analysis of aEEG sleep-wake cycling. At 24 h, 14 of 21 neonates (67\%) with no sleep-wake cycling on visual analysis had a SD minimum amplitude $<1 \mu \mathrm{V}$, compared with two of $41(5 \%)$ of those who had immature or developed sleep-wake cycling $(p=0.000)$.

There was a strong association between low EEG continuity and use of inotropes. At $24 \mathrm{~h}$, EEG continuity was $<80 \%$ at the $10-\mu \mathrm{V}$ level in 12 of 18 neonates $(67 \%)$ who required inotropes, compared with 10 of $46(22 \%)$ who did not require inotropes ( $p=0.001 ;$ Fig. 5). In 14 of 18 neonates (78\%) who received inotropes, there was an increase in EEG continuity at the $10-\mu \mathrm{V}$ level between 12 and $24 \mathrm{~h}$ (including three of four neonates who commenced inotropes between 12 and $24 \mathrm{~h}$ ). Features of normal and abnormal aEEG recordings are illustrated in Figure 6, which shows aEEG recordings at $24 \mathrm{~h}$ in a twin pair born at 24 wk gestation. 
Table 2. aEEG Features at 24 h associated with death or P/IVH

\begin{tabular}{|c|c|c|c|c|}
\hline & $\begin{array}{c}\text { Survivors, no P/IVH, } \\
\quad n=42\end{array}$ & $\begin{array}{l}\text { Survivors, grades 1-2 } \\
\quad \text { IVH, } n=10\end{array}$ & $\begin{array}{l}\text { Died or, grades 3-4 } \\
\quad \text { P/IVH, } n=12\end{array}$ & $p$ \\
\hline \multicolumn{5}{|l|}{ Visual analysis } \\
\hline Suppressed trace aEEG baseline $<2 \mu \mathrm{V}$ & $1(2)$ & $1(5)$ & $4(33)$ & 0.005 \\
\hline No sleep-wake cycling (variability $<2 \mu \mathrm{V}$ ) & $9(21)$ & $3(30)$ & $9(75)$ & 0.011 \\
\hline \multicolumn{5}{|l|}{ Quantitative analysis } \\
\hline$<80 \%$ EEG continuity at $10-\mu \mathrm{V}$ level & $6(14)$ & $6(60)$ & $10(83)$ & 0.000 \\
\hline$<50 \%$ EEG continuity at $25-\mu \mathrm{V}$ level & $9(21)$ & $7(70)$ & $9(75)$ & 0.000 \\
\hline$<30 \%$ EEG continuity at $50-\mu \mathrm{V}$ level & $17(40)$ & $8(80)$ & $11(92)$ & 0.002 \\
\hline Maximum amplitude $<12 \mu \mathrm{V}$ & $4(10)$ & $2(20)$ & $7(58)$ & 0.001 \\
\hline SD minimum amplitude $<1 \mu \mathrm{V}$ & $7(17)$ & $2(20)$ & $7(58)$ & 0.016 \\
\hline
\end{tabular}

Data shown as $n(\%)$.

Table 3. Changes in quantitative measures of EEG continuity and aEEG amplitude in the first $48 \mathrm{~h}$ of life

\begin{tabular}{|c|c|c|c|c|}
\hline & $12 \mathrm{~h}$ & $24 \mathrm{~h}$ & $48 \mathrm{~h}$ & Friedman test, $p$ \\
\hline Survivors: no P/IVH & $n=41$ & $n=42$ & $n=37$ & \\
\hline \multicolumn{5}{|l|}{ EEG continuity (\%) } \\
\hline $10 \mu \mathrm{V}$ & $87.4(68-92)$ & $87.1(82-95)$ & $93.1(85-96)$ & 0.000 \\
\hline $25 \mu \mathrm{V}$ & $53.9(36-64)$ & $58.4(51-67)$ & $66.1(58-73)$ & 0.000 \\
\hline $50 \mu \mathrm{V}$ & $28.6(18-37)$ & $32.8(28-41)$ & $42.6(31-49)$ & 0.000 \\
\hline \multicolumn{5}{|l|}{ aEEG amplitude $(\mu \mathrm{V})$} \\
\hline Maximum & $15.7(12.3-22.6)$ & $17.6(15.2-21.7)$ & $19.6(15.3-23.7)$ & 0.000 \\
\hline Mean & $8.6(6.7-10.6)$ & $9.2(7.9-10.6)$ & $10.2(8.0-11.7)$ & 0.000 \\
\hline Minimum & $4.3(3.5-4.9)$ & $4.6(3.8-5.0)$ & $4.9(3.9-5.8)$ & 0.003 \\
\hline SD minimum amplitude & $1.4(1.1-1.7)$ & $1.4(1.2-1.8)$ & $1.5(1.2-1.8)$ & NS \\
\hline Survivors: grades $1-2 \mathrm{IVH}$ & $n=10$ & $n=10$ & $n=10$ & \\
\hline \multicolumn{5}{|l|}{ EEG continuity $(\%)$} \\
\hline $10 \mu \mathrm{V}$ & $80.1(71-92)$ & $78.5(69-86)^{*}$ & $88.6(77-93)$ & NS \\
\hline $25 \mu \mathrm{V}$ & $43.1(37-57)$ & $43.1(31-57)^{*}$ & $58.3(47-70)$ & NS \\
\hline $50 \mu \mathrm{V}$ & $20.6(16-31)$ & $23.0(15-32)^{*}$ & $29.7(26-43)$ & NS \\
\hline \multicolumn{5}{|l|}{ aEEG amplitude $(\mu \mathrm{V})$} \\
\hline Maximum & $14.8(11.1-16.4)$ & $14.4(12.4-18.6)$ & $16.0(14.7-21.4)$ & 0.027 \\
\hline Mean & $8.0(6.6-8.4)$ & $7.5(6.7-9.4)^{*}$ & $8.5(7.9-10.0)$ & NS \\
\hline Minimum & $4.0(3.5-4.1)$ & $3.5(3.3-4.5)$ & $4.4(3.7-5.1)$ & NS \\
\hline SD minimum amplitude & $1.3(1.0-1.4)$ & $1.3(1.0-1.4)$ & $1.2(1.1-1.4)^{*}$ & NS \\
\hline Died or grades 3-4 P/IVH & $n=11$ & $n=12$ & $n=9$ & \\
\hline \multicolumn{5}{|l|}{ EEG continuity (\%) } \\
\hline $10 \mu \mathrm{V}$ & $75.6(63-82)^{*}$ & $68.1(62-78)^{*}$ & $69.9(58-84)^{*}$ & NS \\
\hline $25 \mu \mathrm{V}$ & $43.3(31-55)^{*}$ & $35.6(27-50)^{*}$ & $40.7(29-50)^{*}$ & NS \\
\hline $50 \mu \mathrm{V}$ & $22.7(14-36)$ & $19.5(17-25)^{*}$ & $21.3(14-29)^{*}$ & NS \\
\hline \multicolumn{5}{|l|}{ aEEG amplitude $(\mu \mathrm{V})$} \\
\hline Maximum & $13.7(7.9-17)$ & $10.3(9.8-15.2)^{*}$ & $14.3(9.1-20.5)$ & NS \\
\hline Mean & $7.1(4.4-8.4)$ & $6.5(5.5-7.5)^{*}$ & $7.0(5.4-11.6)$ & NS \\
\hline Minimum & $3.4(2.4-4.4)$ & $3.5(2.8-4.8)$ & $4.0(2.9-6.9)$ & NS \\
\hline SD minimum amplitude & $0.7(0.6-1.3)^{*}$ & $0.9(0.8-1.2)^{*}$ & $0.9(0.7-1.7)$ & NS \\
\hline
\end{tabular}

Data shown as median (inter-quartile range).

* Mann-Whitney $U$ test: $p<0.05$ compared with "survivors, no P/IVH," for the same time epoch.

\section{DISCUSSION}

This study provides additional information about aEEG data in a large cohort of neonates born before $29 \mathrm{wk}$ gestation and identifies quantitative values that may be used to distinguish between a normal and abnormal aEEG in extremely premature neonates in the first $48 \mathrm{~h}$ of life. On quantitative analysis, EEG continuity $<80 \%$ at the $10-\mu \mathrm{V}$ level was a sensitive and specific marker of poor short-term outcome. By using this marker, we identified $83 \%$ of neonates who died or developed grade 3 or 4 IVH and $60 \%$ of neonates who developed grade 1 or $2 \mathrm{IVH}$, with a positive predictive value for death or any IVH of $73 \%$ and a negative predictive value of $86 \%$. Absence of sleep-wake cycling with baseline variability $<2 \mu \mathrm{V}$ was the strongest predictor of outcome using visual analysis alone. SD minimum amplitude $<1 \mu \mathrm{V}$ was a useful quantitative marker of poor baseline variability.

Assessment of the aEEG in the first few days of life in extremely premature neonates is difficult, as many of the normal features seen in this extremely premature cohort would be considered abnormal in neonates at older ages and gestations. Accurate assessment of the preterm aEEG requires substantial experience with EEG monitoring of the premature neonate to become familiar with normal variants and artifacts. The very discontinuous trace and low aEEG baselines seen in this cohort make visual identification of abnormalities of the background trace difficult; therefore, identification of quantitative measures that can help to distinguish normal from 


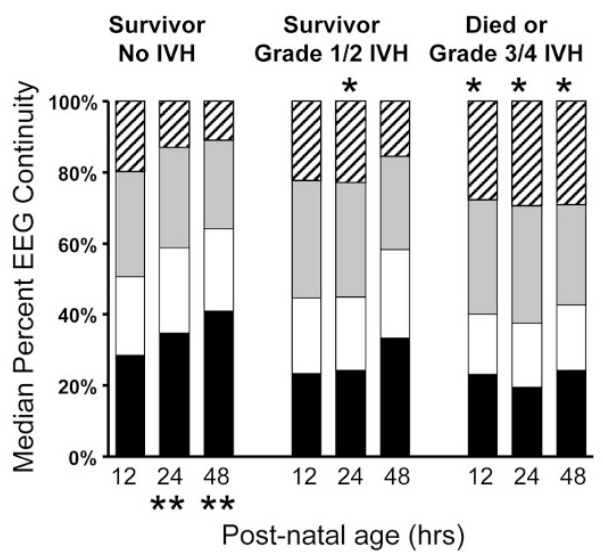

Figure 4. Median group values for percent EEG continuity on quantitative analysis: $50 \mu \mathrm{V}, \square 25 \mu \mathrm{V}, \square 10 \mu \mathrm{V}, \mathbb{Z}<10-\mu \mathrm{V}$ level. ${ }^{*} p<0.05$ compared with "survivor, no P/IVH" for same time epoch. **p $<0.01$ compared with same group values at $12 \mathrm{~h}$.

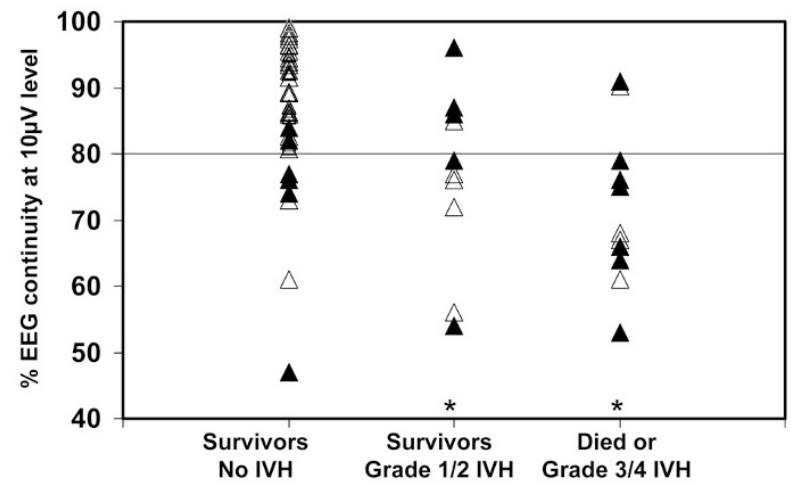

Figure 5. Percentage EEG continuity at $10-\mu \mathrm{V}$ level at $24 \mathrm{~h}$ for neonates treated with inotropes $(\Delta)$ and without inotropes $\left(\Delta .{ }^{*} p<0.001\right.$ for proportion of neonates with EEG continuity $<80 \%$ compared with survivors without IVH.

abnormal may provide an important tool for monitoring extremely premature neonates in the future.

A number of studies have assessed the aEEG in preterm neonates in the first 1-2 wk of life (18-25); however, assessment of the extremely premature neonate using quantitative aEEG measurements has been limited $(20,23,25)$, and little is known about changes in the aEEG in extremely premature neonates in the first $48 \mathrm{~h}$ of life. The data from this study demonstrate lower EEG continuity and aEEG amplitude in the first $24 \mathrm{~h}$ of life than in those that have been reported in neonates at an older age, with an increase over the first $48 \mathrm{~h}$ of life. This is consistent with a previous study (23), which demonstrated an increase in continuity and amplitude in the first week of life in preterm neonates born $<32$ wk gestation. Reasons for the increase in EEG continuity and aEEG amplitude over the first $48 \mathrm{~h}$ of life are unclear. Postulated mechanisms include changes in cerebral blood flow after birth, recovery from physiologic stress at the time of birth, recovery from intensive care treatments such as intubation and surfactant, or increased responsiveness to external stimulation from the environment. Knowledge of this increase in EEG continuity and aEEG amplitude in the first

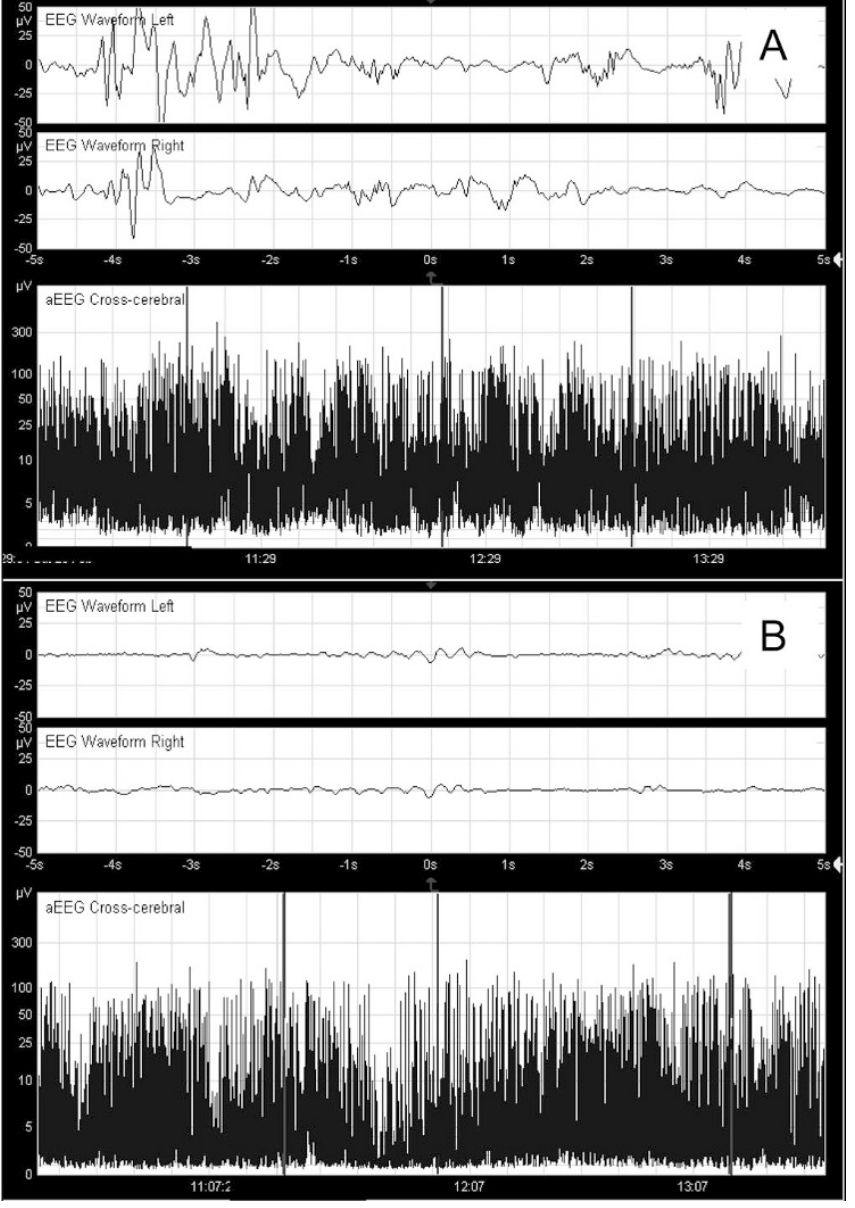

Figure 6. aEEG recordings at $24 \mathrm{~h}$ from twin pair, born at 24-wk gestation, showing $10 \mathrm{~s}$ right and left EEG recordings and $4 \mathrm{~h}$ cross-cerebral (P3-P4) aEEG recording for each twin. A, Twin A: surviving twin, no P/IVH. Discontinuous EEG trace, aEEG baseline 2-5 $\mu \mathrm{V}$, and immature sleep-wake cycling. Quantitative measures: EEG continuity at $10-\mu \mathrm{V}$ level: $86.1 \%$, average aEEG maximum/mean/minimum amplitude: $15.9 / 8.3 / 4.1 \mu \mathrm{V}, \mathrm{SD}$ minimum amplitude: $1.19 \mu \mathrm{V}$. $B$, Twin B: grade $4 \mathrm{P} / \mathrm{IVH}$ at $30 \mathrm{~h}$, death on $\mathrm{d}$ 2. Suppressed EEG, aEEG baseline $<2 \mu \mathrm{V}$, and no sleep-wake cycling. Quantitative measures: EEG continuity at $10 \mu \mathrm{V}$ level: $66.4 \%$, average aEEG maximum/mean/minimum amplitude: 9.9/5.2/1.9 $\mu \mathrm{V}$, SD minimum amplitude: $0.60 \mu \mathrm{V}$.

$48 \mathrm{~h}$ is important, as it highlights that normal values measured in neonates later in the first $1-2$ wk of life may not be appropriate to apply to extremely premature neonates in the first $48 \mathrm{~h}$ of life.

The association between P/IVH and changes in the EEG and aEEG in extremely premature neonates has been seen in previous studies $(19,22,24,29)$. Many of these studies have been performed after the first day of life in neonates who had already developed a P/IVH. In a study of neonates born before $<30$ wk gestation, Olischar et al. (22) found a decrease in early sleep-wake cycling and an increase in discontinuous aEEG activity in neonates with P/IVH compared with healthy preterm neonates on aEEG performed in the first 2 wk of life. Consistent with Olischar et al. (22), we found a decrease in aEEG activity in survivors with lower grades of IVH (grades 1-2 IVH) and more marked depression of the aEEG in those who died or developed grades 3-4 P/IVH, 
although the more subtle changes associated with grades 1-2 IVH were primarily identified in our study using quantitative markers.

Only a few studies have assessed the EEG or aEEG before the onset of the P/IVH $(24,29)$. In our study, head ultrasound examinations were performed on all neonates before commencement of the aEEG recording. Of the seven neonates who developed grade 3 or $4 \mathrm{IVH}$, only two of these had evidence of IVH before $24 \mathrm{~h}$ (both present on first ultrasound at $12 \mathrm{~h}$ ). The remaining five neonates developed acute symptoms associated with head ultrasound evidence of IVH after $24 \mathrm{~h}$. Despite the later appearance of these hemorrhages, the majority of these neonates had evidence of low EEG continuity, low amplitude, and poor aEEG baseline variability present on aEEG monitoring before the development of the IVH. We hypothesize that these earlier aEEG changes are associated with poor cerebral perfusion or hypoxic/ischemic injury in the period leading up to the development of the IVH $(30,31)$.

Our finding of a strong association between low EEG continuity and use of inotropes supports a hypothesis that the low EEG continuity is associated with decreased cerebral perfusion. Inotropes were given on clinical grounds to neonates who had evidence of low BP or clinical and cardiac ultrasound signs of poor perfusion (low cardiac output or low superior vena cava flow). Although we cannot exclude the possibility that the use of inotropes may have contributed to the low EEG continuity found in neonates who received the inotropes, the increase in continuity from 12 to $24 \mathrm{~h}$ in the majority of neonates who received inotropes does not support a causative relationship between inotrope use and low continuity levels. Although the use of inotropes was significantly associated with poor outcome, EEG continuity $<80 \%$ at the $10-\mu \mathrm{V}$ level at $24 \mathrm{~h}$ was a more sensitive predictor of death or IVH than use of inotropes. Among neonates who died or developed IVH, $73 \%$ had EEG continuity $<80 \%$ at the $10-\mu \mathrm{V}$ level at $24 \mathrm{~h}$, however, only $55 \%$ had received inotropes. This provides some evidence that EEG continuity provides a more sensitive predictor of outcome than may be apparent from clinical examination alone.

Studies assessing quantitative aEEG measures and outcome in extremely premature neonates are limited. Wikstrom et al. (25) identified an association between an increase in interburst interval and a decrease in aEEG maximum and minimum amplitude in neonates with P/IVH or white matter damage in the neonatal period and with neurodevelopmental handicap at 2 y. Inder et al. (20) identified an association between cerebral white matter injury and spectral edge frequency in aEEG studies performed in the first $20 \mathrm{~d}$ of life in neonates born before 32 wk gestation. Our study identified a decrease in continuity at the 10-, 25-, and 50- $\mu \mathrm{V}$ levels in neonates with death or IVH; however, low continuity at the $10-\mu \mathrm{V}$ level provided greater sensitivity and specificity for identification of poor short-term outcome in this group of extremely premature neonates.

In conclusion, this study has identified a number of visual and quantitative EEG features of the normal and abnormal
aEEG trace in neonates before 29-wk gestation in the first $48 \mathrm{~h}$ of life. EEG continuity $<80 \%$ at $10-\mu \mathrm{V}$ level was identified as a sensitive and specific marker of poor short-term outcome. By using this marker, we identified $83 \%$ of neonates who died or developed grades 3-4 IVH and $60 \%$ of neonates who developed grades 1-2 IVH, with a positive predictive value for death or any IVH of $73 \%$ and a negative predictive value of $86 \%$. Development of quantitative EEG analysis to allow its use at the bedside may provide a useful clinical tool for monitoring brain activity in extremely premature neonates in the future.

\section{REFERENCES}

1. Doyle LW, Victorian Infant Collaborative Study Group 2004 Evaluation of neonatal intensive care for extremely low birth weight infants in Victoria over two decades. Effectiveness I. Pediatrics 113:505-509

2. Saigal S, Doyle LW 2008 Preterm Birth 3: an overview of mortality and sequelae of preterm birth from infancy to adulthood. Lancet 371:261-269

3. Hellstrom-Westas L, Rosen I 2005 Electroencephalography and brain damage in preterm infants. Early Hum Dev 81:255-261

4. Benda GI, Engel RC, Zhang Y 1989 Prolonged inactive phases during the discontinuous pattern of prematurity in the electroencephalogram of very-low birthweight infants. Electroencephalogr Clin Neurophysiol 72:189-197

5. Biagioni E, Bartalena L, Boldrini A, Cioni G, Giancola S, Ipata AE 1994 Background EEG activity in preterm infants: correlation of outcome with selected maturational features. Electroencephalogr Clin Neurophysiol 91:154-162

6. Hayakawa M, Okumura A, Hayakawa F, Watanabe K, Ohshiro M, Kato Y, Takahashi R, Tauchi N 2001 Background electroencephalographic (EEG) activities of very preterm infants born at less than 27 weeks gestation: a study on the degree of continuity. Arch Dis Child Fetal Neonatal Ed 84:F163-F167

7. de Vries LS, Hellstrom-Westas L 2005 Role of cerebral function monitoring in the newborn. Arch Dis Child Fetal Neonatal Ed 90:F201-F207

8. Eken P, Toet MC, Groenendaal F, de Vries LS 1995 Predictive value of early neuroimaging, pulsed Doppler and neurophysiology in full term infants with hypoxic-ischaemic encephalopathy. Arch Dis Child Fetal Neonatal Ed 73:F75-F80

9. Hellstrom-Westas L, Rosen I, Svenningsen N 1995 Predictive value of early continuous amplitude integrated EEG recordings on outcome after severe birth asphyxia in full term infants. Arch Dis Child Fetal Neonatal Ed 72:F34-F38

10. Toet MC, Hellstrom-Westas L, Groenendaal F, Eken P, de Vries LS 1999 Amplitude integrated EEG 3 and 6 hours after birth in full term neonates with hypoxicischaemic encephalopathy. Arch Dis Child Fetal Neonatal Ed 81:F19-F23

11. Toet MC, van Rooij LG, de Vries LS 2008 The use of amplitude integrated electroencephalography for assessing neonatal neurologic injury. Clin Perinatol 35:665-678

12. Toet MC, Lemmers PM 2009 Brain monitoring in neonates. Early Hum Dev $85: 77-84$

13. Spitzmiller RE, Phillips T, Meinzen-Derr J, Hoath SB 2007 Amplitude-integrated EEG is useful in predicting neurodevelopmental outcome in full-term infants with hypoxic-ischaemic encephalopathy: a meta-analysis. J Child Neurol 22:1069-1078

14. al Naqeeb N, Edwards AD, Cowan FM, Azzopardi D 1999 Assessment of neonatal encephalopathy by amplitude-integrated electroencephalography. Pediatrics 103:1263-1271

15. de Vries LS, Toet MC 2006 Amplitude integrated electroencephalography in the full-term newborn. Clin Perinatol 33:619-632

16. Selton D, Andre M, Hascoet J 2000 Normal EEG in very premature infants: reference criteria. Clin Neurophysiol 111:2116-2124

17. Vecchierini MF, Andre M, d'Allest AM 2007 Normal EEG of premature infants born between 24 and 30 weeks gestational age: terminology, definitions and maturation aspects. Neurophysiol Clin 37:311-323

18. Hellstrom-Westas L, Rosen I, Svenningsen N 1991 Cerebral function monitoring in the first week of life in extremely small low birthweight (ESLBW) infants. Neuropediatrics 22:27-32

19. Hellstrom-Westas L, Klette H, Thorngren-Jerneck K, Rosen I 2001 Early prediction of outcome with aEEG in preterm infants with large intraventricular hemorrhages. Neuropediatrics 32:319-324

20. Inder TE, Buckland L, Williams CE, Spencer C, Gunning MI, Darlow BA, Volpe JJ, Gluckman PD 2003 Lowered electroencephalographic spectral edge frequency predicts the presence of cerebral white matter injury in premature infants. Pediatrics 111:27-33

21. Olischar M, Klebermass K, Kuhle S, Hulek M, Kohlhauser C, Rucklinger E, Pollak A, Weninger M 2004 Reference values for amplitude-integrated electroencephalographic activity in preterm infants younger than 30 weeks' gestational age. Pediatrics 113:e61-e66

22. Olischar M, Klebermass K, Waldhoer T, Pollak A, Weninger M 2007 Background patterns and sleep-wake cycles on amplitude-integrated electroencephalography in preterms younger than 30 weeks gestational age with peri-/intraventricular haemorrhage. Acta Paediatr 96:1743-1750 
23. West CR, Harding JE, Williams CE, Gunning MI, Battin MR 2006 Quantitative electroencephalographic patterns in normal preterm infants over the first week after birth. Early Hum Dev 82:43-51

24. Greisen G, Hellstrom-Westas L, Lou H, Rosen I, Svenningsen N 1987 EEG depression and germinal layer haemorrhage in the newborn. Acta Paediatr Scand 76:519-525

25. Wikstrom S, Ley D, Hansen-Pupp I, Rosen I, Hellstrom-Westas L 2008 Early amplitude-integrated EEG correlates with cord TNF-alpha and brain injury in very preterm infants. Acta Paediatr 97:915-919

26. Kluckow M, Evans N 2000 Superior vena cava flow in newborn infants: a novel marker of systemic blood flow. Arch Dis Child Fetal Neonatal Ed 82:F182-F187

27. Hellstrom-Westas L, Rosen I, de Vries LS, Greisen G 2006 Amplitude-integrated EEG classification and interpretation in preterm and term infants. Neoreviews 7:e76-e87
28. Papille LA, Burstein J, Burstein R, Koffler H 1978 Incidence and evolution of subependymal and intraventricular hemorrhage: a study of infants with birth weights less than 1500 grams. J Pediatr 92:529-534

29. Van de Bor M, Can Dijk JG, Ven Bel F, Brouwer OF, Van Sweden B 1994 Electrical brain activity in preterm infants at risk for intracranial hemorrhage. Acta Paediatr 83:588-595

30. Kissack CM, Garr R, Wardle SP, Weindling AM 2004 Postnatal changes in cerebral oxygen extraction in the preterm infant are associated with intraventricular hemorrhage and hemorrhagic parenchymal infarction but not periventricular leukomalacia. Pediatr Res 56:111-116

31. Kluckow M, Evans N 2000 Low superior vena cava flow and intraventricular haemorrhage in preterm infants. Arch Dis Child Fetal Neonatal Ed 82:F188F194 